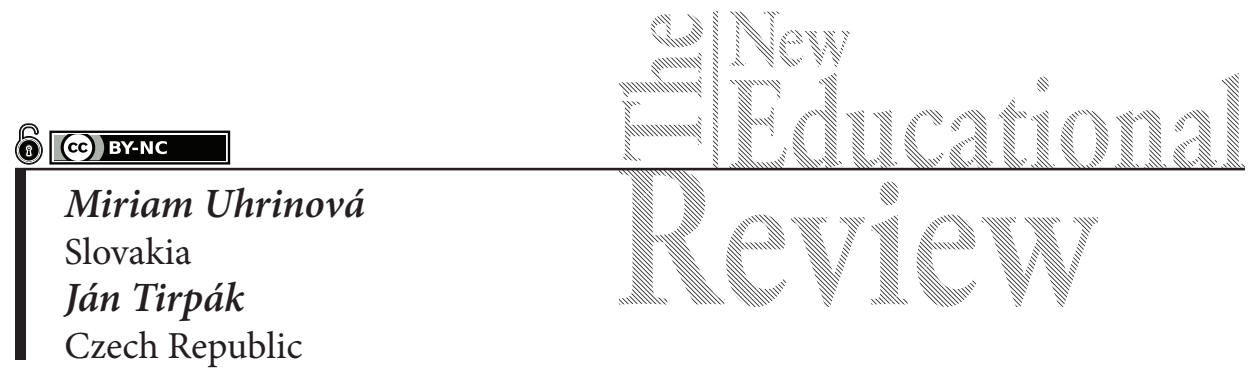

\title{
Teacher's Personality with Regard to Performance Motivation in a Professional Context
}

DOI: $10.15804 /$ tner.2020.59.1.04

\begin{abstract}
In the paper we focused on the personality of the teacher and his/her motivation for professional performance depending on the length of teaching practice. The aim of the research was to find out the profile of the motivational structure of performance in the professional context of primary education teachers and to determine the specifics of individual dimensions related to the motivation for performance. The results showed that the motivational structure of performance is very similar for primary education teachers in the Slovakia and the Czech Republic. For teachers in the Czech Republic, the profile of the motivational structure of their performance does not change with the length of teaching practice. On the other hand, in Slovakia, motivational performance structures change in context depending on the length of teaching practice.
\end{abstract}

Key words: motivation, teacher personality, professional performance, Slovakia, The Czech Republic

\section{Introduction}

The personality of the teacher is an important motivating factor in the educational process. The professional personality of a teacher is the result of his/her own desire to become a teacher, but at the same time it is formed during the undergraduate training in which the prospective teacher begins to shape his/her intuitive concept of teaching and motivation for the teaching profession. Teachers 
can have different reasons and goals for their behavior and activities, and can make unequal efforts to achieve them, also with regard to their performance at work. Job satisfaction and motivation for teachers usually lead to greater work commitment, resulting in better work results and greater effort by teachers to make the education process more effective, even in more challenging conditions, such as education with emphasis on supporting pupils from a low incentive environment. In this context, exploring variables affecting teachers' motivation to pursue a teaching career can be a key issue.

\section{Research Focus}

Current tendencies in the field of education put great demands on the personality of the teacher in terms of his/her performance motivation and motivational profile, the content of which is typical for individual, dominant motivational orientations or tendencies. We are of the opinion that the motivational structure differs diametrically within individual professions and different motivational dispositions are desirable in each of them. Knowing the motivational profile of a teacher enables an understanding of individual manifestations and the whole complex of their behavior or actions. Each teacher is motivated in the dimensions of their motivational structure. It is for this reason that we want to focus on the profile of the motivational structure of performance of teachers of primary education in a professional context. Inner satisfaction from the work of a teacher is a very important factor in why a person decides to become a teacher and then further develop their profession (Spear et al., 2000; Moran et al., 2001). Teacher motivation is related to what makes teachers happy, satisfied, self-sacrificing and committed to show the best performance in educating their pupils (Nayana \& Mustiary Begum, 2017; Akhtar \& Iqbal, 2017). Motivation is a critical variable in educational institutions (Akhtar \& Iqbal, 2017; Robinns et al., 2009). There is considerable research that reflects factors that affect job satisfaction and increase motivation for performance (Kitching, Morgan \& O'Leary, 2009; Fasasi et al., 2015; Mustafu \& Othman, 2010; Geofrey et al. 2010). Some research has confirmed that leadership style has a significant impact on job satisfaction (Bhatti et al. 2012; and Wang et al., 2015). The results have shown that the majority of teachers have an internal motivation for professional performance, reinforced by widespread recognition, success and advancement and vocation, job satisfaction and understanding of their goals in life. Research also points to the existing relationship between teacher's internal motivation for professional performance and their impact on pupil's motivation to learn (Roth et al. 2007; Mustafa \& Othman, 2010; Gorozidis \& Papaioannou, 2014). Teachers with a strong internal motivation to achieve more 
often apply pupil-activating methods in the educational process. Thus, low motivation among teachers may have a negative impact on achieving high standards in education (Kocabas, 2009). At the same time, research has shown that problems associated with the teaching profession lead to demotivation among teachers and are often linked to retirement. Often the cause is not only the workload, or low pay, but also pupils who come from eg. a low-spirited environment and need more attention and more effort at work (Kitching, Morgan \& O'Leary, 2009). Thus, the motivation profile of a teacher can also be influenced by age and the length of teaching experience. Motivation is thus often neglected in practice, but it plays an important role. From the perspective of helping professions within the framework of comprehensive rehabilitation, motivation is important not only for the given professions, but also for the other side, i.e. the clients or pupils. If individuals are well motivated, they also improve the outcomes (Vostrý et al., 2019).

\section{Methodology of Research}

\section{General Background of Research}

This empirical research was quantitative and qualitative. The subject of the research was the motivational structure of teachers in Slovakia and the Czech Republic and the study of selected determinants of motivation for professional performance.

In this paper, we want to focus on the presentation of research results, the aim of which was to determine the profile of the motivational structure of performance in the professional context of teachers at primary school, in a comparison of teachers in the Czech and Slovak Republics and to identify the specifics of each dimension related to the motivation to perform in a professional context. We started from the following research questions:

- What are the differences in the profile of the motivational structure of performance in the professional context of primary education teachers?

- What is the importance of individual dimensions related to motivation to perform in the professional context for selected groups of respondents to the research?

- Does the length of teaching practice affect the profile of the motivational structure of performance in the professional context of teachers?

These research questions also served to formulate the following research hypotheses: 
$\mathrm{H}_{01}$ : The profile of the motivational structure of performance among primary school teachers in Slovakia and the Czech Republic is not different.

$\mathrm{H}_{02}$ : The importance of individual dimensions regarding motivation to perform in a professional context does not differ among selected respondents of the research.

$\mathrm{H}_{03}$ : The length of teaching practice does not affect the motivational profile of the performance structure of primary school teachers in Slovakia and the Czech Republic.

\section{Sample of Research}

Our research plan was carried out using a questionnaire method during 2019 on a sample of 138 primary school teachers in the Czech Republic and Slovakia. The first group consisted of 73 teachers from the Czech Republic, the total average age was 36 years, with an average length of 12 years of teaching practice. The second group was represented by 65 teachers from the Slovak Republic. The average age of teachers was 39 years and the average time of practice was 15.5 years. The choice of schools was intentional considering their number in individual regions of Slovakia and the Czech Republic. Most teachers come from larger towns and villages and fewer from schools in small villages. We interviewed two prominent pedeutologists from each country in the research. Pedeutologists were selected deliberately and are working at some of the best universities in the Czech Republic and Slovakia.

\section{Instrument and Procedures}

A standardized LMI-Motivationinventory Incentive Questionnaire (Shuler et al., 2011) was chosen to collect the necessary quantitative empirical research data. The internal consistency coefficients (Crobnach $\alpha$ ) for all incremental samples were calculated to verify the reliability of the overall score and the scores in each dimension. With reference to the table in the manual, the authors state that the values range between 0.68 and 0.86 and that the items are valid in terms of content, as their formulation is anchored in the theory of performance motivation. Correlations between scales range from 0.34 to 0.63 (Schuler et al., 2011). The length of teaching practice and the age of respondents are considered as independent variables in this research. With regard to qualitative research data, a structured interview was used.

\section{Data Analysis}

Mathematical-statistical operations were used to process and analyze the results. For the sake of transparency and clarity of data, we present data processing using 
graphs and tables. To calculate the data we used the so-called Student's t-test and analysis of variance (ANOVA) at a significance level of $\alpha=0.05$. The data were first subjected to the Shapiro-Wilk's test of normality of the data distribution. For the statistical evaluation of the data obtained by the research version 15.2.00 of the software Statgraphics Centurion XV was used and Microsoft Excel.

\section{Results of Research}

The motivational profile represents, over time, a relatively stable characteristic of a person's personality, the content of which is dominated by motivational orientations or tendencies, or their composition. One of the objectives of our research was to find out the profile of the motivational structure of performance in a professional context in a comparison of primary education teachers in the Czech and Slovak Republics. These countries were selected for comparison quite intentionally, because in most features the structure of the Czech education system is similar to the structure of the Slovak one. The education principle in both school systems is based on similar educational programs. For the presented data we work with the following abbreviations, which will be explained in more detail. The final version of the questionnaire consists of 170 items, which are assigned to 17 scales (dimensions). The total mean value of all items is 4.55 with a minimum of 2.61 and a maximum of 6.32. Data refer to a sample of $\mathrm{N}=1671$ test experimental persons.

The final authoritative concept of 17 dimensions (scale) of performance motivation in a professional context includes the following personality traits involved in self-performance: stamina (VY), dominance (DO), engagement (AN), confidence in success (DU), flexibility (FX), flow (FL), fearlessness (NE), internality (IN), compensatory effort $(\mathrm{KU})$, pride in performance $(\mathrm{HV})$, willingness to learn $(\mathrm{OU})$, difficulty preference (PO), independence (SA), self-control (SK), status orientation (OS), competitiveness (SO), purposefulness (CV) and overall score (CS).

The basic profile of teacher's motivational performance structure in the sample we follow is shown in Chart 1, where most of the averages of the resulting teacher's motivational performance structure profiles are above the mean value. When comparing the research set, we find very similar (almost identical) motivational structures of performance in the professional context of both groups of teachers.

In addition to the findings of these profiles, we also compared teacher's motivational structure profiles in relation to the above-mentioned characteristics. Statistical analysis performed using Student's t-test showed significant differences in dominance, which are statistically significantly better rated by teachers in the Czech Republic. Confidence in success, on the other hand, is statistically more favorably assessed among teachers of the Slovak Republic. 


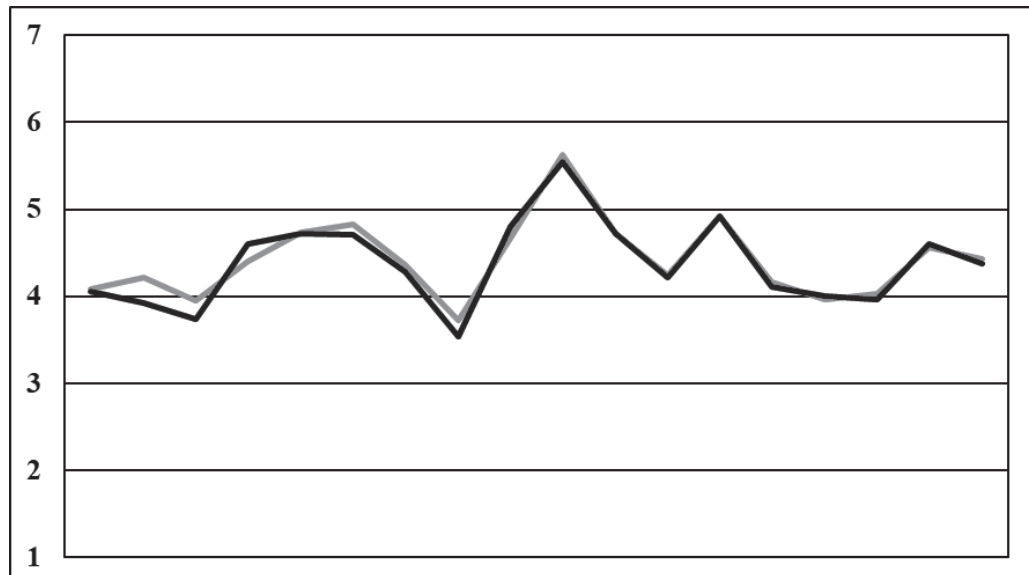

VY DO AN DU FX FL NE IN KU HV OU PO SA SK OS SO CV CS

teachers from the Czech Republic $\square$ teachers from Slovakia

Chart 1: Profile of the Motivational Structure of Performance in the Professional Context by Arithmetic Average of Response for Teachers in Slovakia and the Czech Republic

The intervening variable of the research investigation was the length of teaching practice, which is certainly more relevant to the teaching profession than age itself. In particular, it should be considered that most teachers in the primary education system are women, many of whom spend a relatively short, or longer, period on maternity leave, thus reducing the length of their teaching practice. Therefore, in international comparisons, it is preferable to operate with length of practice in examining the impact of teaching characteristics on educational processes and their outcomes, rather than just the age of teachers. We were wondering whether there was a change in the overall profile of the motivational structure of performance in the professional context of teachers depending on the length of their teaching practice. The results are presented with respect to the Czech Republic, in Chart 2 and with respect to the Slovak Republic, in Chart 3.

Within the ANOVA analysis, it was found that for teachers in the Czech Republic, the profile of motivational performance structures does not change in the professional context with the length of teaching practice.

In terms of research investigation and ANOVA analysis results at the significance level $\alpha=0.05$ for teachers in the Slovak Republic depending on the length of teaching practice, we can conclude that there is a statistically significant difference between the groups selected for comparison. 


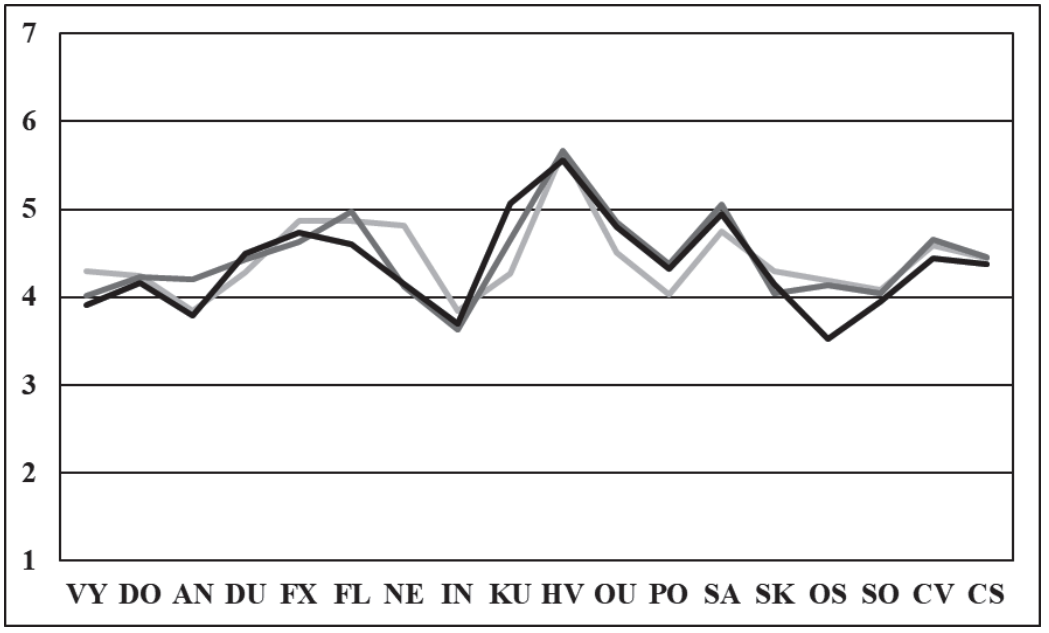

[53]

teachers from the Czech Republic with 0-9 years of teaching practice; $\square$ teachers from the Czech Republic with 10-19 years of teaching practice; $\square$ teachers from the Czech Republic with more than 20 years of teaching practice

Chart 2: Profile of the Motivational Structure of Performance in the Professional Context by Arithmetic Mean Response of Teachers in the Czech Republic with Dependence on the Length of Teaching Practice

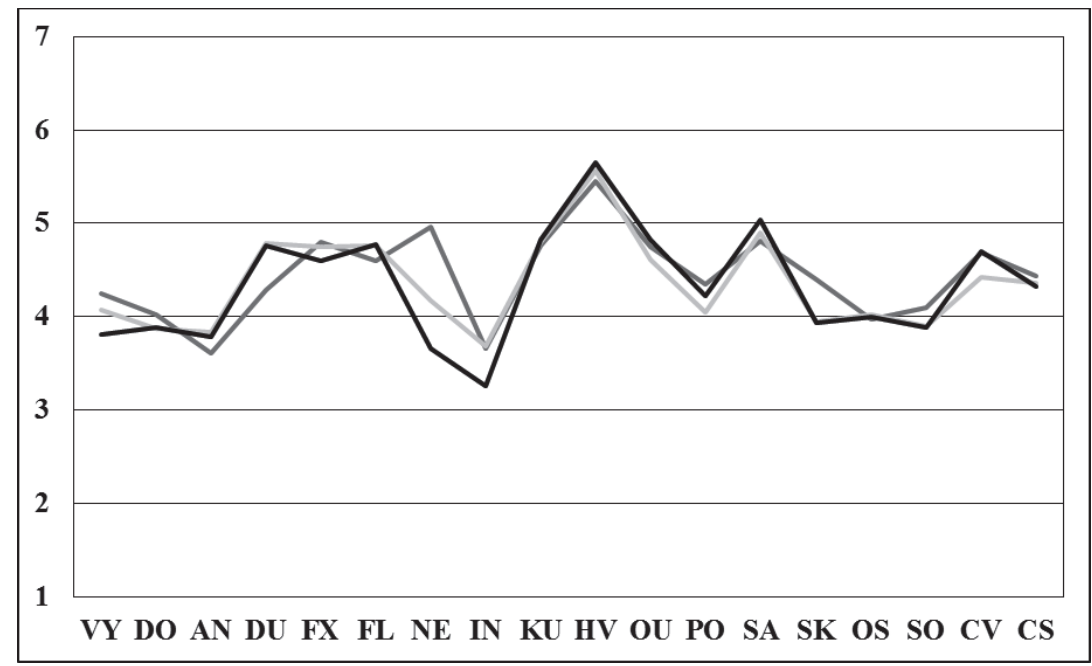

teachers in Slovakia with 0-9 years of teaching practice; $\square$ teachers in Slovakia with 10-19 years of teaching experience; teachers in Slovakia with more than 20 years of teaching experience

Chart 3: Profile of the motivational structure of performance in a professional context according to the arithmetic mean of responses of teachers in Slovakia in relation to the length of teaching experience 
In addition to the discovery of this difference, we further compared the above-mentioned group of respondents in terms of the guiding concepts of 17 dimensions of motivation to perform in a professional context. The statistical analysis performed showed significant differences in the following scales: persistence, fearlessness, internality and self-control, which are statistically significantly more highly evaluated among teachers in Slovakia with a duration of practice of 0-9 years. In contrast, confidence in success is assessed by teachers in Slovakia with more than 20 years of work experience as being statistically significantly more valuable.

To complete this data, we conducted a structured interview with two prominent pedeutologists from the Czech and Slovak Republics. The interview also addressed the following questions:

- What do you think motivates primary education teachers the most to stay in their profession?

- Which motivational tool do you consider to be the most important for further professional development of teachers?

- Do you think that teachers change the profile of the motivational structure of their professional performance with regard to their age or length of teaching experience?

On the basis of data processing, it can be stated that an excellent teacher can be defined according to five characteristics, which can also be described as areas of professional development for teachers. According to the pedeutologists, the teacher must have vision and be able to teach. S/he has an understanding of the skills and knowledge needed to teach. Furthermore, the practice that allows him/ her to teach and the ability to reflect on his/her own, that is, s/he is able to learn from experience. Finally, but just as important as the other things mentioned above, is the teacher's own motivation.

In this respect, it has been found that it is most motivating to retain primary education teachers in the profession to influence the development of children and youth. However, the further education system and the evaluation system also play an important role, as does the work environment in terms of space, personnel and material security. Here the results of our survey correlate with results showing high preference among teachers in terms of willingness to learn, making compensatory efforts and having pride in performance. However, according to Pedeutology, the most important tool for motivation and for further professional growth of teachers is the further education of pedagogical staff, which include courses that correspond to the needs of teachers in the range further education on offer, regular expansion of professional knowledge, skills self-fulfillment and self-satisfaction, 
and providing financial and non-financial benefits to teachers who are actively involved in further education. However, the economic and working conditions of the teaching profession also play a particularly important role.

In terms of the findings of the survey and the opinions of the pedeutologists, we tend to change the motivation profile depending on the length of teaching practice, which is certainly a more relevant characteristic of the teaching profession than age itself. In this respect, we therefore assume that research work on teacher motivation should take into account, in particular, the length of their teaching experience.

\section{Discussion}

Based on the research we have found that the motivational structure of performance in professional contexts is very similar (almost identical) among teachers of primary education in the Slovak and Czech Republic. In addition to the findings of these profiles, we further compared the guiding concepts of the 17 dimensions (scales) of motivation to perform in a professional context and identified for which variables statistically significant differences existed. The following areas: dominance and engagement, are statistically significantly better rated by teachers in the Czech Republic. On the other hand, confidence in success is statistically more favorable for teachers in the Slovak Republic. In our view, this is a multifactorial issue and gives the possibility of further follow-up research in terms of why these dimensions are statistically differently evaluated by teachers. The length of teaching practice is considered as an independent variable in the empirical research.

Multiple data comparisons have shown that the profile of motivational performance structures does not change in the professional context for teachers in the Czech Republic. From the results of teachers in the Slovak Republic, a statistically significant difference was found between the selected groups, which was related to respondents with the length of practice of $0-9$ years and 20 years and more. In addition to finding this difference, we compared the guiding concept of 17 dimensions (scales) of motivation to perform in a professional context. The statistical analysis carried out showed significant differences in the scales: perseverance, confidence in success, fearlessness, internality and self-control. The arithmetic means of responses show a statistical difference in the items on perseverance, fearlessness, internality and self-control, which are statistically significantly more highly evaluated among teachers in the Slovak Republic with a duration of practice 
of 0-9 years. In contrast, confidence in success is assessed by teachers in Slovakia with more than 20 years of work experience as statistically significantly more valuable. In our opinion, the results present the decisive stages of the teaching profession and the characteristics that are typical of teachers who are just starting their careers and also those who have long teaching experience in the profession.

\section{Conclusions}

The research carried out indicates the need to monitor and study the motivation for professional performance of teachers at present. The motivation of teachers to perform usually leads to more work commitment, which results in better work results and more effort for teachers to make more enormous efforts to streamline the educational process, even in more challenging conditions, such as education with a view to supporting pupils from environments with low levels of stimulation in the educational process, which is currently very often solved. During the research, we have seen that primary education teachers prefer areas such as dominance, engagement and confidence in success in terms of motivational structure.

Research shows that primary education teachers in the Slovak and Czech Republics have a very similar (almost identical) motivational structure of performance in a professional context. The results of the research show that the motivational structures of performance in the professional context of teachers in Slovakia vary depending on the length of teaching practice.

Motivation to perform in a professional context can be seen as a phenomenon occurring in the complex context of the internal and external environment, in a complex of interdependent, conditioned and variable factors. Its full understanding therefore requires understanding of the individual elements of this system and their interaction. A growing problem for European education systems is the lack of teachers, particularly in certain subjects or in specific regions. In some countries, the aging teacher population and the perception of the overall low prestige associated with the teaching profession may increase the pressure on education systems. Some studies (TIMSS 2015) attribute this fact to a decline in prestige, worsening teacher working conditions and their relatively low salaries compared to salaries in other intellectual professions. One way to support and strengthen the teaching profession is to emphasize factors that are positively linked to overall satisfaction with the work of teachers and the perception of its importance, and secondly to the school environment and working conditions. As Vostrý (2018) mentions, motivation can be considered as an essential element, which is an integral part of all 
workers in the so-called helping professions. However, it should not be forgotten that the other party must also be motivated, i.e. pupils or persons with whom direct educational/rehabilitation activities are performed.

\section{Acknowledgements}

This article was supported by Catholic University in Ružomberok as a grant KEGA No. 012KU-4/2019.

\section{References}

Akhtar, J.H., Iqbal, I. (2017). Impact of Motivation on Teachers' Job Performance: A Case Study of a Public Sector University. Journal of Educational Sciences \& Research Spring, 4(1). http://uos.edu.pk/Journals

Bhatti, N., Maitlo, G.M., Shaikh, N., Hashmi, M.A., Shaikh, F.M. (2012). The Impact of Autocratic and Democratic leadership style on Job Satisfaction. International Business Research, 5(2), 192.

Gorozidis, G., Athanasios G.P. (2014). Teachers' Motivation to Participate in Training and to Implement Innovations. Teaching and Teacher Education. 39: 1-11.

Kitching, K., Morgan, M., O'Leary, M. (2009). It's the Little Things: Exploring the Importance of Commonplace Events for Early-Career Teachers' Motivation. Teachers and Teaching, 15(1): p. 43-58. DOI: 10.1080/13540600802661311.

Kocabas, I. (2009). The Effects of sources of Motivation on Teachers' Motivation Levels. Education, 129(4), 724-733.

Moran, A., Kilpatrick, R., Abbott, L., Dallat, J., McClune, B. (2001). Training to Teach: Motivating Factors and Implications for Recruitment. Evaluation and Research in Education, 15(1), 17-32.

Mustafa, M., Othman, N. (2010). The effect of work motivation on teacher's work performance in Pekanbaru senior high schools, Riau Province, Indonesia. Sosiohumanika, $3(2), 259-272$.

Nayana L.M., Mustiary B.P. (2017). Teacher Motivation and Classroom Teaching a Study with Reference to Teychers of Selected Primary Schools in Mangalore. Sahyadri Journal of Management (SJOM), 1(1), 54-64.

Robbins, S., Judge, T., Sanghi, S. (2009). Organizational Behavior (13 ${ }^{\text {th }}$ Ed.). New Delhi: Pearson Education.

Roth, G., Avi, A., Yaniv, K.M., Haya, K. (2007). Autonomous Motivation for Teaching: How Self-Determined Teaching May Lead to Self-Determined Learning. Journal of Educational Psychology, 99(4), 761-774.

Schuler, H. at al. (2011). LMI -Leistungsmotivationsinventar / Dotazník motivace k výkonu. Praha: Testcentrum.

Spear, M., Gould, K., Lee, B. (2000). Who would be a teacher? A review of factors motivating 
and demotivating prospective and practising teachers. Slough: National Foundation for Educational Research.

Veteška, J., Paulovčáková, L. (2018). Management and Marketing of Educational Institutions. Karlsruhe: Ste-Com.

Vostrý, M. (2018). Education of seniors with respect to their cognitive functions. Palma, Mallorca, Spain: INTED2018 Proceedings.

Vostrý, M. (2018). Selected opportunities for access to geriatric clients from the perspective of assisting professions. Journal of Education Culture and Society, 8(1), 89-95. DOI: https://doi.org/10.15503/jecs20181.89.95.

Vostrý, M., Zilcher, L. (2019). Effectiveness of combination therapy for people with cerebrovascular disease from the perspective of helping professions. ICERI2019 Proceedings. Spain: IATED Academy. DOI: 10.21125/iceri.2019.1078.

Wang, F.J., Chich-Jen, S., Mei-Ling, T. (2010). Effect of leadership style on organizational performance as viewed from human resource management strategy. African Journal of Business Management, 4(18), 3924-3936. 